\title{
Overcoming Innovation Resistance beyond Status Quo Bias - A Decision Support System Approach (Research-in-Progress)
}

\author{
Carola Stryja \\ Karls ruhe Institute of \\ Technology \\ carola.stryja@kit.edu
}

\author{
Verena Dorner \\ Karlsruhe Institute of \\ Technology \\ verena.dorner@kit.edu
}

\author{
Lara Riefle \\ Karls ruhe Institute of \\ Technology \\ lara.riefle@student.kit.edu
}

\begin{abstract}
When innovative products and services are launched to the market, many consumers initially resist adopting them, even if the innovation is likely to enhance their life quality. Explanations for this behavior can also be found in specific personality traits and in general pitfalls of human decisionmaking. We believe that decision support systems (DSS) can help alleviate such innovation resistance. We propose a DSS design that addresses innovation resistance to complex innovations on an individual's cognitive level. An experimental study will be conducted to test the influence of different DSS modifications on the perception and selection of complex innovations. We aim to identify levers for reducing innovation resistance and to derive DSS design implications.
\end{abstract}

\section{Introduction}

Many consumers initially resist adopting innovative products and services even if adopting the innovation is likely to enhance their life quality. A well-known example for innovation resistance is the case of the simplified personal computer keyboard developed by August Dvorak in 1932. Although many studies show that it increases typing efficiency, consumers resist adopting it; mostly because they are unwilling to invest retraining effort [1].

Another area in which innovation and innovation resistance have been very publicly debated over the past decade is electric mobility. From an environmental and social perspective, large-scale introduction of electric cars would help to reduce environmental pollution [2]. In Germany, for instance, the government promotes the adoption of electric cars in order to meet the climate goals of the European Union, i.e. reducing greenhouse gas emissions of passenger cars by $60 \%$ between 1990 and 2050, by way of research funding and purchase incentives [3].

But the transition to electric car technologies requires a "new notion of mobility" (p.532) which challenges established mobility routines and habits [4]. Such changes inevitably evoke fear and resistance, and have led to low acceptance of electric cars among the majority of consumers [2], [5]-[7].

Even in settings where usage costs for conventional and electric cars are nearly identical, and when car range is sufficient for consumer needs, consumers mostly decide against electric cars [8]. Taken together with the finding that consumers' perceptions change towards a much more positive opinion towards electric cars once they have tested one [5], we believe that initial perceptions of this innovation are likely biased by consumers' innate innovation resistance.

In this paper, we draw on theory from organizational change and behavioral economics to explain why consumers refrain from adopting complex innovations (like electric cars) even if it would benefit them. We then propose to use these theoretical insights for designing a decision support system (DSS) for debiasing complex innovation adoption decisions [9]. DSS are intended to increase the effectiveness of decisions or efficiency of decision processes by providing decision makers with relevant information [10]. DSS are typically implemented as information systems supporting decision makers in forecast and optimization scenarios [11], [12]. Our intention is to expand the application of DSS to the field of innovation adoption decisions. The focus of our research is in designing a DSS in order to help people overcome resistance towards the adoption of complex innovations. For the empirical investigation of our research model and DSS, we choose the case of the electric cars due to their technological complexity and potential implications for environment, business, infrastructure, and individual mobility patterns. 
Our core research question can thus be stated as follows: How can a web-based DSS be designed to support consumers to overcome resistance to innovation?

The remainder of the paper proceeds as follows: Section 2 gives an overview of related work. Section 3 introduces the research model and hypotheses of the study. Section 4 describes the methodology proposed to test the hypotheses. Section 5 concludes the paper with a discussion of the topic and its contribution to existing theory.

\section{Theoretical Background}

Although much research on technology and innovation adoption exists, comparatively few studies address consumer resistance to innovations [13]. Main contributions have been made in the fields of organizational change, e.g. [14]-[17], user resis tance to IT systems, e.g. [18]-[22], and marketing and consumer behavior theory, e.g. [7], [23]-[30].

\subsection{Innovation Resistance}

The behavior of resisting an innovation is not simply the opposite of adoption [24]. Resistance to innovations, to change in general, is a normal reaction of humans [31]. Humans have an intrinsic desire to maintain a psychological equilibrium and any change in behavior is likely to disturb this equilibrium state [32]. Innovations usually bring with them some form of change due to their novelty and thus cause initial resistance [29], [33]. As such, the resistance caused by innovations is more a resistance to the behavioral change imposed than to the innovation itself [29], [34].

Three forms of resistance behavior can be observed [7], [31]. First, consumers may postpone the adoption decision to a later point of time [35]. Postponement behavior generally occurs when consumers consider the innovation as currently too immature or expensive or when they are unsure about concrete use case scenarios [7]. Second, consumers may reject the innovation. Rejection is the decision not to adopt the innovation after an active evaluation [36]. Third, consumers may oppose an innovation. This occurs when consumers so strongly reject an innovation that they decide to attack its diffusion. Opposition behavior can be observed in relation to technologies that are highly controversial like nuclear power or genetic engineering [7].

Which behavior a consumer will engage in is not only due to the nature of the innovation but also to the personality of the consumer and their perceptions of the innovation, which in turn are shaped by the way it is presented [20], [28], [37], [38].

Dispositional resistance to change is a personality trait that describes intrinsic unwillingness to change current behavior or attitude [39]. [15] posits four distinct elements of dispositional resistance to change: routine seeking, emotional reaction to imposed change, cognitive rigidity, and short-term focus (e.g. [21], [39], [40]).

Routine-seeking and emotional reaction to change are closely interrelated [15]. The emotional reaction to change, i.e. an individual's ability to manage the psychological stress induced by changing situations, affects openness towards change in general [15]. The fear of losing emotional control over life situations when change occurs results in seeking routines [15]. Often, routine seeking is aligned with an innate tendency to express a form of personal dogmatism which manifests in unwillingly accepting alternative ideas or perspectives. Such tendencies generally become more pronounced with the degree of novelty of the innovation [27].

Cognitive rigidity is mainly related to organizational change but also hampers consumer openness to innovations [39]. It can be described as closed-mindedness which results in an unwillingness to adapt to changing situations [15]. Individuals who exhibit enduring resistance behavior are more likely to choose low levels of stimulation and novelty in their lives and have a disinclination towards giving up old habits [39].

Finally, short-term focus refers to the individual's reluctance to undergo the learning and adaptation period necessary for coping with change [15]. Shortterm focus results in a misperception of short-term pain and long-term benefit due to the innovation adoption. Individual decision makers have the tendency to ignore long-term over short-term gains, e.g. by spending money today rather than saving for retirement [41].

Another dispositional trait that are often observed in combination with resistance, specifically rejection behavior is innate conservatism [7], [18], [42], [43].

In the context of work studies, user resistance research shows that, aside from personality, changes in work routines and technology perception are important resistance determinants in the context of work as maintaining the status quo, i.e. using the current IS is perceived as more beneficial than changing to the new IS [21]. Resistance caused by change in work routines is caused, for instance, by unwillingness to put in the cognitive effort to learn how to execute tasks within the new system. Only if the new system is perceived as useful and beneficial will resistance to changing working routines lessen [20], [21], [44], [45]. 
Individuals tend to favor the status quo over change even when the benefits of changing outweigh the status quo. [43] call such behavior "status quo bias". There are a number of possible reasons why individuals exhibit status quo bias [19]. In the context of innovation resistance, the following appear most interesting: sunk cost effects, regret minimization, and consistency bias [29], [43]. Preference for the status quo increases with the sunk costs invested in the status quo [19]. Regret is felt more keenly when bad outcomes are the result of changes away from the status quo than of inaction [46]. Finally, decisions that deviate from "standard" decisions - like deciding to adopt an innovation - usually cause some form of cognitive dissonance, which decision makers in general prefer to avoid [43].

In our study, we concentrate on the dimension of personality-based dispositional resistance to change and aim to understand why people reject innovations even when the innovation would be beneficial, e.g. because the innovation offers additional features for the same price as the product the consumer already uses, and how resistance behavior can be alleviated by means of a decision support systems (DSS). Thus, we will not consider innovation-specific barriers but focus on the cognitive and situational antecedents of innovation resistance [39].

\subsection{Overcoming Innovation Resistance with Choice Architecture}

Choice architecture is grounded in the domain of behavioral economics and aims to shape decision behavior by consciously designing the decision setting [47]. The way a decision is presented affects the decision process [48]. Behavioral economics show that humans often base their decisions on automated thinking processes which may introduce biases in decision making [47]. Choices should be designed in a way that decision makers in "automatic" mode more likely choose those options that they would choose when deciding rationally [49]. The goal of choice architecture is thus to design and incorporate small features or nudges in the decision making process in order to highlight better alternatives for the users and assist them in choosing a desired option, while not restricting their freedom of choice [50]. The concept of "nudging" decision makers in a certain direction often a socially desired behavior - has gained much and controversial interest in practice and science [51]. While the use of choice architecture undoubtedly means undertaking some form of influence, it is important to say that any way a choice is presented to the decision maker has an effect on the decision process, no matter if there is a specific intention behind it or not [48], [52], [53].

Choice architecture can be applied in multiple ways and in a variety of application scenarios (see Table 1 in the Appendix for applications to support environmental conservation behavior) [50], [54]-[66]. Nudging towards environmental conservation behavior, for instance, can take the form of placing consumptiondependent emoticons on energy bills - or information about one's own and the neighbors' average consumption. Being compared with their neighbors encourages hous eholds towards consuming less energy [49], [57], [67]. Organ donation is another example which shows the efficacy of choice architecture. In most countries, low willingness to donate organs after having been declared braindead is contrasted by a high demand for organs. To increase donation rates, some European countries introduced an opt-out policy, effectively changing the default option for their entire populations, by which everyone is a donor until they actively opt out.

This policy change had a huge impact - the opt-out country Austria, for instance, now counts $99 \%$ of the population as donors while the opt-in country Germany still counts only $12 \%$ of the population as donors [68].

Nudging elements have also been applied in the innovation decision context in an experimental study in [69]. Innovation rejection was decreased when the innovation was set as default. So-called "innovation novices" in particular relied on default settings. One limitation of the study, however, is the incremental type of innovation used (USB cell for recharging mobile devices), which led the authors to call for a replication of their results in more complex innovation contexts [69]. In addition, only status quo satisfaction was considered as determinant for innovation resistance. Individual inclination to change was not examined although it plays a major role in innovation adoption decisions [28]-[30], [39].

\subsection{Resistance towards Complex Innovations: the Case of Electric Cars}

Existing studies on innovation resistance are often limited to the fact that they test consumer resistance with simple and small innovations such as a USB cells [69] or mobile phones with an innovative battery technology [28]. Complex innovations usually require higher consumer commitment in terms of financial involvement or changes in habits and routines.

Electric cars meet these criteria. Buying a car is expensive, and even second-hand electric cars may require substantial investment due to battery ageing [70]. Electric cars also require changes in routines, for instance remembering to charge the battery, and habits, 
for instance adapting long driving routes to the shorter range of electric cars and infrastructure available [5]. However, the main concern expressed by consumers (limited driving range) has been shown to weigh disproportionately in their decision not to adopt electric cars: the range of most car rides necessary for daily activities falls below the critical driving range [71] Arguments in favor of electric cars (e.g., silent driving, stronger acceleration, more sustainable lifestyle) affect the decision surprisingly little, even though many consumers cite driving experience as important for their choice of car and sustainability as something they aspire to in general [6], [71].

There are several studies which examine consumer resistance towards electric cars, although beyond the theoretical context of innovation and user resistance theory. [71] focus on driving range as major psychological barrier for the acceptance of electric cars. Based on an empirical study they examine the individual perceptions of a comfortable driving range and its antecedents (e.g., personality traits, coping skills). [72] integrate emotions towards car driving and electric cars and show that emotions and attitude are the strongest predictors of usage intention, followed by subjective norm. [73] analyze barriers to sustainable solutions and natural gas vehicles in the automotive sector.

In summary, electric cars have a high social and economic relevancy but face high resistance expressed by consumers [6], [71], [72]. While some studies have examined (psychological) barriers to the adoption of electric cars, research on cognitive and behavioral factors that influence the adoption decision is scarce. We contribute to current innovation resistance res earch by applying choice architecture to the case of complex innovations, esp. electric cars. Our research aims to generate knowledge on how such complex innovations should be presented in order to enhance adoption probability.

\subsection{Decision Support Systems (DSS)}

The purpose of DSS can be to increase the effectiveness of decisions or the efficiency of decision processes by providing decision makers with relevant information [10],[74]. DSS are designed to compensate weaknesses in human decision making by providing decisional guidance and specific system features such that finding and choosing the best option is made easier [12], [75]. According to [76], a DSS should enable the decision maker to capitalize on their strengths while compensating for their weaknesses. As design artifacts, DSS are information systems with which the decision maker interacts via an interface [11]. The design of the DSS artifact thus plays a crucial role in the decision making process as it determines how decision makers perceive their choice options and which decision they will take [12], [77].

\section{Research Model}

In our study, we aim to apply theoretical knowledge about innovation resistance to the design of a DSS that helps consumers overcome cognitive innovation resistance. To reiterate, we only consider the case of adoptions which would be beneficial for the consumer.

We follow the approach of [75] who proposes the definition of a design strategy that determines the setup of the single DSS features. The design strategy in this study is characterized by guiding decision processes such that decision makers are more likely to select innovative products or services over standard alternatives - provided that the decision maker benefits from choosing the innovative products. For this, tools proposed by choice architecture will be used. We draw upon the concept of "digital nudging" which refers to "the use of user interface design elements to guide people's choices or influence users' inputs in online decision environments." (p.3) [53]. Specifically, we propose implementing two choice architecture tools, setting defaults and priming, in a web-based DSS such that decision makers are encouraged to consider innovations instead of rejecting them directly.

\subsection{De pendent Variable: Innovation Adoption Decision (Choice)}

Dispositional resistance to change is an internal psychological trait which cannot be manipulated by external variables [20]. Rather, contextual factors moderate the influence of dispositional resistance to change on perceptions of the innovation and resistance behavior. Our dependent variable is resistance behavior, i.e. the decision to select or reject the innovation ("innovation adoption decision").

\subsection{Moderating Variables: Default and Priming}

In our study, we will test the moderating effect of two variables (default and priming) on the influence of dispositional resistance to change on choice behavior. A default is the option which is chosen when the decision maker refuses to decide [49]. While the principle of pre-selecting an option is simple, its power has been shown in many decision making studies [47], [78]. People tend to stick to the alternative that is preselected for them, especially if they are novices with 
regard to the decision situation, i.e. lacking expertise to evaluate the situation comprehensively [78]. To stick to the default option relieves the decision maker from having to invest time and cognitive effort or money in the decision. Furthermore, defaults can be understood as some form of recommendation from policymakers that suggest socially desired behavior [68]. As people usually struggle with synthesizing conflicting goals such as protecting the environment and saving money, using defaults may support decisions in favor of sustainable behavior and thus offer a promising way to nudge consumers towards choosing electric cars [79].

Priming refers to the mechanism when (un)conscious memories of an individual are activated by an external stimulus to enhance the absorption of new stimuli [80]. Priming cues can be any stimuli that reach the consciousness, such as words, sights or smells [81]. Studies on priming show that small stimuli suffice to change behavior [82]. [83] show that people who are exposed to words they associate with a specific behavior tend to behave according to these words (e.g. the word "athletic" triggered fitness behavior). Showing the picture of a smiling face induced people to drink more than when they were exposed to a frowning face [80]. Based on [83] we assume that a pro-innovation slogan displayed to the decision maker while processing the innovation adoption decision will have a positive effect on the willingness to select the innovation. We will therefore apply priming in our DSS to enhance the probability of innovation selection.

3.2.1. Defaults and Routine Seeking. People who show resistance to change are less willing to give up old and long established habits [17]. Especially change not initiated by themselves will be resisted due to fear of losing control over the situation [15]. People who tend to resist perceive change as a stressor because their familiar behavior does not match the new situation. Hence, change in general is associated with stress, which hampers an open and unbiased approach to new situations [58]. As a result, decision makers perceive regret for bad outcomes from new actions as stronger than similar outcomes resulting from inaction [46]. We therefore expect that:

Hypothesis 1 (H1): If the DSS pre-selects the innovation as default option, decision maker's routine seeking behavior will be reduced.

3.2.2. Defaults and Cognitive Rigidity. Cognitive rigidity reduces the openness towards trying out innovative products and services [84]. Addressing cognitive rigidity with choice architecture requires addressing the trait of dogmatism but also fear of failure, insecurity and low success expectations [15], [85]. We believe that defaults could be an appropriate means to design decision scenarios which partly negate cognitive rigidity of the decision maker. Default options can indicate a socially desired behavior and may motivate people with low self-esteem and fear of failure to follow the recommendation made by the DSS [68]. We therefore expect that:

Hypothesis 2 (H2): If the DSS pre-selects the innovation as default option, decision maker's cognitive rigidity will be negatively affected.

\subsubsection{Priming and Emotional Reaction to Imposed} Change. The degree to which an individual is open to change also depends on their level of psychological resilience. Change causes uncertainty, and resilience enables people to cope with the stress that comes with uncertainty [86]. Individuals with a low level of psychological resilience often have a lower need for stimulation and are more unwilling to change - also due to the implication that changing one's behavior could be taken as a signal that practices of the past were fallacious [15]. Using a priming mechanism that promotes the sustainable effect of electric cars may trigger positive emotions and enhance the self-efficacy of the decision maker such that selecting the innovation becomes more attractive. We therefore expect that:

Hypothesis 3 (H3): If the DSS uses a priming mechanism which works in favor of the innovation, decision maker's emotional reaction to imposed change will be negatively affected.

3.2.4. Priming and Short-Term Focus. The adaptation to a changing situation requires time and effort. Although the long-term benefit caused by the behavioral change may make it worthwhile to endure the adjustment period, decision makers often suffer from their short-term focus and perceive the pain as sociated with change as higher than the benefit [87]. The higher the degree of newness and discontinuity of an innovation, the stronger the resistance to put effort into adjusting to it [27]. Priming decision makers before they decide may enhance the perceived longterm benefit of selecting the innovation such that pain associated with adjusting to the change will be perceived as less powerful. We therefore expect that:

Hypothesis 4 (H4): If the DSS uses a priming mechanism which works in favor of the innovation, decision maker's short-term focus will be negatively affected. 


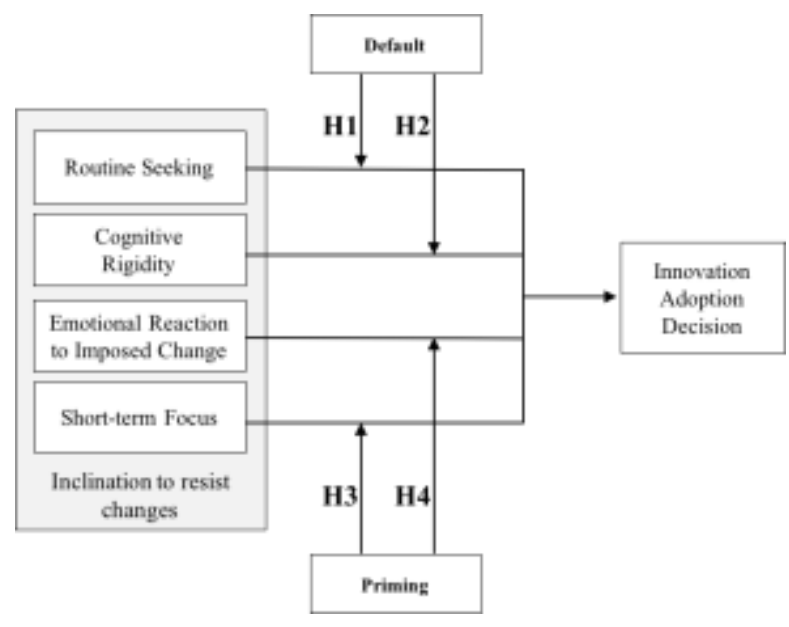

Figure 1. Research model

Figure 1 summarizes our hypotheses and research model.

To conclude, we assume that resistance to innovations can be alleviated with the help of a DSS that uses the principles of default and priming. The hypotheses will be tested by conducting an experimental study which will be described in the next section.

\section{Experimental Study}

Electric cars can be adopted in multiple ways, e.g. by purchasing or leasing them, using them as shared or rental cars or within corporate fleets. Since most of these scenarios require some form of online decision process (e.g., car configurator, booking platform), a web-based DSS will be designed and tested in an experimental study. The innovation adoption decision will be framed as a car renting scenario. The rationale behind this choice of framing is, first, that a car rental platform loosely corresponds to - or at the very least that it can be implemented as - a DSS. Second, our sample is more likely to be familiar with renting a car than buying or leasing a car, or using it within a corporate context. Third, we believe that it is more likely that subjects will exhibit choice behavior in the lab similar to their behavior in the real world, due to the reduced economic consequences of renting a car and the possibility of adequately incentivizing the subjects (e.g., with a car rental voucher).

\subsection{Research Design}

The study will be conducted using a $2 \times 2 \times 2$ within-subject design. The three factors are defaults (pre-selection of e-car; no pre-selection), priming (yes versus no) and scenario (inner city trip; nearby family trip). For our first experiment, the sample will consist of university students. In later experiments, we plan to extend the sample to participants from other demographic groups in order to increase generalizability of our results. In particular, we will aim to sample participants from different age groups, with different degrees of dependency on their cars, and different daily driving ranges.

\subsection{Procedure}

The experiment will be set up as the imitation of a car rental booking platform in which the participants can choose between traditional cars and electric cars.

Participants will be given two scenarios in which they have to choose a rental car for a trip. The trip is either a short-distance inner city shopping trip (scenario 1) or a medium-distance day visit to family and friends (scenario 2). Both scenarios are compatible with range restrictions of electric cars. Rental costs may be assumed as being equal compared to traditional cars. Participants can choose between different car models some of which are electric cars. Each car is described by a number of technical attributes relevant to the decision maker. During the selection process, it is planned to collect behavioral data via mouse and eye tracking to evaluate the effect of nudging mechanisms applied [52]. Collecting such data allows gaining a better insight in how and why default and priming (do not) work.

Participants receive questionnaires on their inclination to resist change, their general attitude towards innovations and electric cars as well as their experience with electric cars after the experiment [15], [39].

\section{Conclusion}

The research in progress proposed in this paper builds upon existing research from innovation resistance theory and behavioral economics in order to shed more light on the interplay between cognitive and situational features of innovation adoption decisions and how they affect individual innovation resistance. In a laboratory experiment with the specific setting "electric car innovation", we plan to analyze the effect of a variety of choice architecture tools on individual decision behavior and innovation resistance. The study examines how external factors (default and priming) moderate the influence of dispositional resistance to change on innovation choice behaviour, i.e. the choice to adopt or resist an innovation. 
Our research also aims at deriving design principles for DSS that help overcome resistance towards complex innovations. We apply our research to the case of electric cars due to their technological complexity and potential implications for environment, business, infrastructure, and individual mobility patterns.

\subsection{Theoretical Contribution}

The proposed research contributes to existing theory in several ways. So far, theoretical contributions to the area of innovation resistance are limited to experimental studies with small and simpler products such as a USB cells [69] or mobile phones with an innovative battery technology [28]. Our study complements this research by examining the choice processes for complex innovations. We apply findings from user resistance in organizations, e.g. [20], [21] to the domain of consumer behavior to examine how the complex innovation is perceived by the subjects (technology perception) and how this perception influences choice behavior.

To the best of our knowledge, this is the first study to examine the interplay of dispositional resistance to innovation and different choice architecture tools, and how they affect resistance behavior. Insights on this issue may offer valuable starting points for further studies in innovation resistance theory, adoption of electric car research and applied behavioral economics in general.

\subsection{Expected Managerial Implications}

The general question of how consumers will react towards an innovation before it is launched is an important aspect for companies as well as governments. Findings from our study will support the design of online interfaces that aim to address innovation resistance on a cognitive level. Knowledge about resistance patterns of their consumers and how cognitive resistance to change may be alleviated by design elements of the communication interface can be a valuable support for companies who launch and sell their innovative products via online platforms. Policymakers can profit from our findings with regard to the design of interfaces that promote sustainable behavior.

\section{References}

[1] P. A. David and B. P. A. David, "Clio and the Economics of QWERTY," Am. Econ. Rev., vol. 75, no. 2, pp. 332-337, 1985.

[2] P. Jochem, S. Babrowski, and W. Fichtner, “Assessing
CO2 Emissions of Electric Vehicles in Germany in 2030," Transp. Res. A Policy Pract., vol. 78, pp. 68-83, 2015.

[3] N. Abdelkafi, S. Makhotin, and T. Posselt, "Business Model Innovations for Electric Mobility - What Can Be Learned From Existing Business Model Patterns?," Int. J. Innov. Manag., vol. 17, no. 1, p. 1340003, Feb. 2013.

[4] S. Steinhilber, P. Wells, and S. Thankappan, "Sociotechnical inertia: Understanding the barriers to electric vehicles," Energy Policy, vol. 60, pp. 531-539, Sep. 2013.

[5] F. Bühler, P. Cocron, I. Neumann, T. Franke, and J. F. Krems, "Is EV experience related to EV acceptance? Results from a German field study," Transp. Res. Part F Traffic Psychol. Behav., vol. 25, no. PART A, pp. 34-49, 2014.

[6] K. Dudenhöffer, "Why electric vehicles failed," $J$. Manag. Control, vol. 24, no. 2, pp. 95-124, 2013.

[7] M. Kleijnen, N. Lee, and M. Wetzels, "An exploration of consumer resistance to innovation and its antecedents," $J$. Econ. Psychol., vol. 30, no. 3, pp. 344-357, 2009.

[8] H. Holzer, "Die Spannung lässt nach," Zeit Online, 2015. [Online]. Available: http://www.zeit.de/mobilitaet/2015-09/carsharingelektroauto-probleme. [Accessed: 14-Jun-2016].

[9] D. Ariely, Predictably Irrational. New York: HarperCollins, 2008.

[10] Ramesh Sharda, S. H. Barr, and J. C. McDonnell, "Decision Support System Effectiveness : A Review and an Empirical Test," Manage. Sci., vol. 34, no. 2, pp. 139-159, 1988.

[11] D. J. Power, Ramesh Sharda, and F. Burstein, Decision support systems. John Wiley \& Sons, Ltd, 2015.

[12] S. T. March and V. C. Storey, "Design science in the information systems discipline: an introduction to the special issue on design science research.," MIS Q., pp. 725-730, 2008.

[13] S. Laumer, "Why Do People Reject Technologies - a Literature-Based Discussion of the Phenomena 'Resistance To Change' in Information Systems and Managerial Psychology Research," ECIS 2011 Proceedings, Pap. 60, 2011.

[14] S. Oreg, M. Bayazit, M. Vakola, L. Arciniega, A. Armenakis, R. Barkauskiene, N. Bozionelos, Y. Fujimoto, L. González, J. Han, M. Hřebíčková, N. Jimmieson, J. Kordačová, H. Mitsuhashi, B. Mlačić, I. Ferić, M. K. Topić, S. Ohly, P. Ø. Saksvik, H. Hetland, I. Saksvik, and K. van Dam, "Dispositional resistance to change: Measurement equivalence and the link to personal values across 17 nations.," J. Appl. Psychol., vol. 93, no. 4, pp. 935-944, 2008.

[15] S. Oreg, "Resistance to change: Developing an individual differences measure," J. Appl. Psychol., vol. 88, no. 4, pp. 680-693, 2003.

[16] S. K. Piderit, "Rethinking Resistance and Recognizing Ambivalence: A Multidimensional View of Attitudes toward an Organizational Change," Acad. Manag. J., vol. 25, no. 4, pp. 783-794, 2000.

[17] G. Watson, "Resistance to change," Am. Behav. Sci., vol. 14, pp. 745-766, 1971.

[18] H. Kim and A. Kankanhalli, "Investigating User Resistance to Information Sy stems Implementation: A Status Quo Bias Perspective," MIS Q., vol. 33, no. 3, pp. 567-582, 2009. 
[19] G. L. Polites and E. Karahanna, "Shackled to the Status Quo: the Inhibiting Effects of Incumbent System Habit, Switching Costs, and Inertia on New System Acceptance," MIS Q., vol. 36, no. 1, pp. 21-42, 2012.

[20] S. Laumer, C. Maier, A. Eckhardt, and T. Weitzel, "User personality and resistance to mandatory information systems in organizations: A theoretical model and empirical test of dispositional resistance to change," J. Inf. Technol., vol. 31, pp. 67-82, 2016.

[21] S. Laumer, C. Maier, A. Eckhardt, and T. Weitzel, "Work Routines as an Object of Resistance During Information Systems Implementations: Theoretical Foundation and Empirical Evidence," Eur. J. Inf. Syst., vol. 25, pp. 317-343, 2016.

[22] S. Laumer, "Why do people reject technologies: A review of user resistance theories," Inf. Syst. Theory, vol. 28, pp. 63-86, 2012.

[23] R. P. Bagozzi and K.-H. Lee, "Consumer Resistance to, and acceptance of, Innovations," Adv. Consum. Res., vol. 26, no. 1, pp. 218-225, 1999.

[24] M. C. Claudy, R. Garcia, and A. O'Driscoll, "Consumer resistance to innovation - a behavioral reasoning perspective," J. Acad. Mark. Sci., vol. 43, no. 4, pp. 528-544, 2014.

[25] T. Laukkanen, S. Sinkkonen, M. Kivijärvi, and P. Laukkanen, "Innovation resistance among mature consumers," J. Consum. Mark., vol. 24, no. 7, pp. 419-427, 2007.

[26] S. Ram, "A model of innovation resistance," $A d v$. Consum. Res., vol. 14, no. 1, pp. 208-212, 1987.

[27] S. Ram and J. N. Sheth, "Consumer Resistance to Innovations: The Marketing Problem and its solutions," $J$. Consum. Mark., vol. 6, no. 2, pp. 5-14, 1989.

[28] S. Heidenreich, T. Kraemer, and M. Handrich, "Satisfied and unwilling: Exploring cognitive and situational resistance to innovations," J. Bus. Res., vol. 69, no. 7, pp. 2440-2447, 2016.

[29] K. Talke and S. Heidenreich, "How to Overcome ProChange Bias: Incorporating Passive and Active Innovation Resistance in Innovation Decision Models," J. Prod. Innov. Manag., vol. 31, no. 5, pp. 894-907, 2013.

[30] S. Heidenreich and T. Kraemer, "Innovations Doomed to Fail? Investigating Strategies to Overcome Passive Innovation Resistance," J. Prod. Innov. Manag., vol. 33, no. 3, pp. 277-297, 2015.

[31] I. Szmigin and G. Foxall, "Three forms of innovation resistance: the case of retail payment methods," Technovation, vol. 18, no. 6-7, pp.459-468, 1998.

[32] C. E. Osgood and P. H. Tannenbaum, "The principle of congruity in the prediction of attitude change.," Psychol. Rev., vol. 62, no. 1, pp. 42-55, 1955.

[33] J. N. Sheth, "Psychology of Innovation Resistance: The Less Developed Concept in Diffusion Research," Res. Mark., vol. 4, no. January, pp. 273-282, 1981.

[34] R. R. McCrae and P. T. Costa, "Validation of the fivefactor model of personality across instruments and observers.," J. Pers. Soc. Psychol., vol. 52, no. 1, pp. 81-90, 1987.

[35] P. Laukannen, S. Sinkonnen, and T. Laukannen, "Consumer Resistance to Internet banking: postponers, opponents and rejectors," Int. J. Bank Mark., vol. 24, no. 7, pp. 419-427, 2007.

[36] E. Rogers, "New product adoption and diffusion," $J$. Consum. Res., vol. 2, no. 4, pp. 290-301, 1976.

[37] C. W. Park, S. Y. Jun, and D. J. Macinnis, "Choosing What I Want versus Rejecting What I Do Not Want: An Application of Decision Framing to Product Option Choice Decisions," J. Mark. Res., vol. 37, no. 2, pp. 187-202, 2000.

[38] E. Romero, P. Villar, M. Á. Luengo, and J. A. GómezFraguela, "Traits, personal strivings and well-being," J. Res. Pers., vol. 43, no. 4, pp. 535-546, 2009.

[39] S. Heidenreich and M. Handrich, "What about Passive Innovation Resistance? Investigating Adoption-Related Behavior from a Resistance Perspective," J. Prod. Innov. Manag., vol. 32, no. 6, pp. 878-903, 2014.

[40] S. Laumer, C. Maier, and A. Eckhardt, "Why do they Resist? - An Empirical Analysis of an Individual's Personality Trait Resistance regarding the Adoption of New Information Systems," ECIS 2010 Proceedings. Pap. 31., 2010 .

[41] D. Kahneman and A. Tversky, "Prospect Theory: an Analysis of Decision Under Risk," Econometrica, vol. 66, no. 3, pp. 497-527, 1979.

[42] S. Laumer and A. Eckhardt, "Why do People Reject Technologies? Towards an Understanding of Resistance to IT-induced Organizational Change," ICIS 2010 Proc., no. $151,2010$.

[43] W. Samuelson and R. Zeckhauser, "Status quo bias in decision making," J. Risk Uncertain., vol. 1, no. 1, pp. 7-59, 1988.

[44] C. Maier, S. Laumer, A. Eckhardt, and T. Weitzel, "Who really quits?," ACM SIGMIS Database, vol. 46, no. 4, pp. 26-47, 2015.

[45] R. Agarwal and J. Prasad, "Are individual differences germane to the acceptance of new information technologies?," Decis. Sci., vol. 30, no. 2, pp.361-391, 1999. [46] D. Kahneman and A. Tversky, "Choices, values, and frames," Am. Psychol., vol. 39, no. 4, p. 341, 1984.

[47] D. G. Goldstein, E. J. Johnson, A. Herrmann, and M. Heitmann, "Nudge your customers toward better choices," Harv. Bus. Rev., vol. 86, no. 12, 2008.

[48] E. J. Johnson, S. B. Shu, B. G. C. Dellaert, C. Fox, D. G. Goldstein, G. Häubl, R. P. Larrick, J. W. Payne, E. Peters, D. Schkade, B. Wansink, and E. U. Weber, "Beyond nudges: Tools of a choice architecture," Mark. Lett., vol. 23, no. 2, pp. 487-504, 2012.

[49] R. H. Thaler, C. R. Sunstein, and J. P. Balz, "Choice architecture," in The Behavioral Foundation of Policy, E. Shafir, Ed. Princeton University Press, 2013, pp. 428-439.

[50] P. Brown, "A Nudge in the Right Direction? Towards a Sociological Engagement with Libertarian Paternalism," Soc. Policy Soc., vol. 11, no. 3, pp. 305-317, 2012.

[51] E. Selinger and K. Whyte, "Is There a Right Way to Nudge? The Practice and Ethics of Choice Architecture," Sociol. Compass, vol. 5, no. 10, pp.923-935, 2011.

[52] C. Schneider, M. Weinmann, and J. von Brocke, "Choice architecture: Using fixation patterns to analyze the effects of form design on cognitive biases," Inf. Syst. Neurosci. Proc. Gmunden Retreat NeuroIS 2015, pp.91-97, 2015.

[53] M. Weinmann, C. Schneider, and J. von Brocke, "Digital Nudging," http://ssrn.com/abstract=2708250, 2015. 
[54] H. Allcott, "Social norms and energy conservation," http://ceepr.mit.edu/files/papers/2009-014.pdf, 2009.

[55] J. M. Burger, "The foot-in-the-door compliance procedure: A multiple-process analysis and review," Personal. Soc. Psychol. Rev., vol. 3, no. 4, pp. 305-325, 1999.

[56] R. Cialdini, "Crafting normative messages to protect the environment," Curr. Dir. Psychol. Sci., vol. 12, pp. 105109, 2003.

[57] P. G. Hansen and A. M. Jespersen, "Nudge and the Manipulation of Choice: A Framework for the Responsible Use of the Nudge Approach to Behaviour Change in Public Policy," J. Risk Regul., vol. 4, no. 1, pp. 3-28, 2013.

[58] A. . Harrison and R. B. Zajonc, "The effects of frequency and duration of exposure on response competition and affective ratings," J. Psychol., vol. 7, pp. 163-169, 1970.

[59] S. Iyengar, R. Wells, and B. Schwartz, "Doing better but feeling worse: looking for the 'best' job undermines satisfaction.," Psychol. Sci., vol. 17, pp. 143-150, 2006.

[60] R. L. Keeney, "Value-focused thinking: identifying decision opportunities and creating alternatives," Eur. J. Oper. Res., vol. 92, pp. 537-549, 1996.

[61] J. Levav, M. Heitmann, A. Herrmann, and S. S. Iyengar, "Order in Product Customization Decisions: Evidence from Field Experiments," J. Polit. Econ., vol. 118, no. 2, pp. 274-299, 2010.

[62] S. B. Shu, "Future-biased search: the quest for the ideal," J. Behav. Decis. Mak., vol. 21, pp. 352-377, 2008.

[63] J. . Martin and M. I. Norton, "Shaping online consumer choice by partitioning the web," Psychol. Mark., vol. 26, p. 908-926., 2009.

[64] D. J. Cook and W. Z. Song, "Ambient intelligence and wearable computing: sensors on the body, in the home, and beyond," J. Ambient Intell. Smart Environ., vol. 1, pp. 83-86, 2009.

[65] R. P. Larrick and J. B. Soll, "The MPG illusion," Science (80-. )., vol. 320, pp. 1593-1594, 2008.

[66] E. Peters, N. F. Dieckmann, D. Västfjäll, C. K. Mertz, P. Slovic, and J. Hibbard, "Bringing meaning to numbers: the impact of evaluative categories on decisions," J. Exp. Psychol., vol. 15, pp. 213-227, 2009.

[67] A. Alemanno and A. Spina, "Nudging legally: On the checks and balances of behavioral regulation," Int. J. Const. Law, vol. 12, no. 2, p. 429-456., 2014.

[68] D. Pichert and K. V. Katsikopolous, "Green defaults: Information presentation and pro-environmental behaviour," J. Environ. Psychol., vol. 28, pp. 63-73, 2008.

[69] S. Kuester, S. C. Hess, and A. Herrmann, "The Role of Defaults in Preventing Innovation Rejection," Int. J. Innov. Manag., vol. 19, no. 2, pp. 1550023-1-1550023-23, 2015.

[70] V. V. Viswanathan and M. Kintner-Meyer, "Second use of transportation batteries: Maximizing the value of batteries for transportation and grid services," IEEE Trans. Veh. Technol., vol. 60, no. 7, pp. 2963-2970, 2011.

[71] T. Franke, I. Neumann, F. Bühler, P. Cocron, and J. F. Krems, "Experiencing Range in an Electric Vehicle:
Understanding Psychological Barriers," Appl. Psychol., vol. 61, no. 3, pp. 368-391, 2012.

[72] I. Moons and P. De Pelsmacker, "Emotions as determinants of electric car usage intention," J. Mark. Manag., vol. 28, no. 3-4, pp. 195-237, 2012.

[73] K. P. Wiedmann, N. Hennigs, L. Pankalla, M. Kassubek, and B. Seegebarth, "Adoption barriers and resistance to sustainable solutions in the automotive sector," J. Bus. Res., vol. 64, no. 11, pp. 1201-1206, 2011.

[74] C. A. Looney and A. M. Hardin, "Decision Support for Retirement Portfolio Management: Overcoming Myopic Loss Aversion via Technology Design," Manage. Sci., vol. 55 , no. 10, pp. 1688-1703, 2009.

[75] M. S. Silver, "Decisional support systems: Directed and nondirected change," Inf. Syst. Res., vol. 1, no. 1, pp. 105-122, 1990.

[76] S. Hoch and D. Schkade, "A Psychological Approach to Decision Support Systems.," Manage. Sci., vol. 42, no. 1, pp. 51-64, 1996.

[77] V. K. Vaishnavi and W. Kuechler, Design science research methods and patterns: innovating information and communication technology. Crc Press, 2015.

[78] C. R. Sunstein and R. H. Thaler, "Libertarian Paternalism Is Not An Oxymoron," Univ. Chicago Law Rev., vol. 70, no. 4, pp. 1159-1202, 2003.

[79] J. R. Irwin, P. Slovic, S. Lichtenstein, and G. H. McClelland, "Preference reversals and the measurement of environmental values," J. Risk Uncertain., vol. 6, no. 1, pp. 5-18, 1993.

[80] P. Winkielman, "Unconscious Affective Reactions to Masked Happy Versus Angry Faces Influence Consumption Behavior and Judgments of Value," Personal. Soc. Psychol. Bull., vol. 31, no. 1, pp. 121-135, 2005.

[81] P. Dolan, M. Hallsworth, D. Halpern, D. King, R. Metcalfe, and I. Vlaev, "Influencing behaviour: The mindspace way," J. Econ. Psychol., vol. 33, no. 1, pp. 264$277,2012$.

[82] J. a. Bargh, "What have we been priming all these years? On development, mechanisms, and ecology of nonconsious social behavior.," Eur. J. Soc. Psychol., vol. 36, no. 2, pp. 147-168, 2006.

[83] A. Dijksterhuis and J. A. Bargh, "The perceptionbehavior expressway: Automatic effects of social perception on social behavior," Adv. Exp. Soc. Psychol., vol. 33, pp. 140, 2001.

[84] C. M. Lau and R. W. Woodman, "Understanding organizational change: A schematic perspective," Acad. Manag. J., vol. 38, p. 537, 1995.

[85] S. Pally, "Cognitive rigidity as a function of threat," $J$. Pers., vol. 23, no. 3, pp. 346-55, 1955.

[86] T. A. Judge, C. J. Thoresen, V. Pucik, and T. M. Welbourne, "Managerial coping with organizationalchange: A dispositional perspective," J. Appl. Psychol., vol. 84, pp. 107-122, 1999.

[87] R. M. Kanter, "Managing the human side of change," Manage. Rev., vol. 74, pp. 52-56, 1985. 


\section{Appendix}

Table 1. Tools of Choice Architecture and their application in environmental conservation scenarios

\begin{tabular}{|c|c|c|}
\hline \multirow{2}{*}{\begin{tabular}{|l|l}
$\begin{array}{l}\text { choice } \\
\text { architecture } \\
\text { tool }\end{array}$ & $\begin{array}{l}\text { decision } \\
\text { scenario }\end{array}$ \\
\end{tabular}} & \multicolumn{2}{|c|}{ environmental conservation } \\
\hline & energy & transport \\
\hline $\begin{array}{c}\text { Affect } \\
\text { Dolan et al. (2012) }\end{array}$ & Alemanno and Spina (2014) & \\
\hline \multicolumn{3}{|l|}{$\begin{array}{l}\text { Commitments } \\
\text { Dolan et al. (2012) }\end{array}$} \\
\hline $\begin{array}{l}\text { Defaults } \\
\text { Thaler et al. (2013) }\end{array}$ & Pichert and Katsikopolous (2007) & $\begin{array}{l}\text { Park, Jun, and MacInnis (2000) } \\
\text { Avineri (2009) } \\
\text { Bothos et al. (2014) }\end{array}$ \\
\hline $\begin{array}{c}\text { Ego } \\
\text { Dolan et al. (2012) }\end{array}$ & Burger (1999), Dolan et al. (2012) & Burger (1999), Dolan et al. (2012) \\
\hline \multicolumn{3}{|l|}{$\begin{array}{l}\text { Expect Error } \\
\text { Thaler et al. (2013) }\end{array}$} \\
\hline $\begin{array}{l}\text { Focus on satisficing } \\
\text { Dolan et al. (2012) }\end{array}$ & & Shu (2008), Iyengar et al. (2006) \\
\hline $\begin{array}{l}\text { Giving Feedback } \\
\text { Thaler et al. (2013) }\end{array}$ & $\begin{array}{l}\text { Thaler, Sunstein, and Balz (2014) } \\
\text { Alemanno and Spina (2014) } \\
\text { Hansen and Jespersen (2013) }\end{array}$ & Thaler, Sunstein, and Balz (2014) \\
\hline $\begin{array}{l}\text { Incentives } \\
\text { Thaler et al. (2013) }\end{array}$ & Thaler, Sunstein, and Balz (2014) & Thaler, Sunstein, and Balz (2014) \\
\hline $\begin{array}{c}\text { Norms } \\
\text { Dolan et al. (2012) }\end{array}$ & $\begin{array}{c}\text { Cialdini (2003) } \\
\text { Allcott (2009) }\end{array}$ & \\
\hline $\begin{array}{c}\text { Priming } \\
\text { Dolan et al. (2012) }\end{array}$ & Hansen and Jespersen (2013) & \\
\hline $\begin{array}{c}\text { Salience, attribute parsimony } \\
\text { and labeling } \\
\text { Dolan et al. (2012), Johnson et al. (2012) }\end{array}$ & $\begin{array}{l}\text { Thaler, Sunstein, and Balz (2014) } \\
\text { Peters et al. (2009) } \\
\text { Johnson et al. (2012) } \\
\text { Hansen and Jespersen (2013) }\end{array}$ & $\begin{array}{c}\text { Peters et al. (2009) } \\
\text { Johnson et al. (2012), Keeney (1996) }\end{array}$ \\
\hline $\begin{array}{l}\text { Structure complex choices, } \\
\text { decision staging, partitioning of options } \\
\text { Thaler et al. (2013), Johnson et al. (2012) }\end{array}$ & Johnson et al. (2012) & $\begin{array}{l}\text { Levav et al. (2010) } \\
\text { Martin and Norton (2009) }\end{array}$ \\
\hline $\begin{array}{l}\text { Technology and decision aids } \\
\text { Johnson et al. (2012) }\end{array}$ & $\begin{array}{l}\text { Cook and Song (2009) } \\
\text { Johnson et al. (2012) }\end{array}$ & $\begin{array}{l}\text { Cook and Song (2009) } \\
\text { Johnson et al. (2012) }\end{array}$ \\
\hline $\begin{array}{l}\text { Understanding mappings } \\
\text { Thaler et al. (2013) }\end{array}$ & $\begin{array}{l}\text { Larrick and Soll (2008) } \\
\text { Johnson et al. (2012) }\end{array}$ & Larrick and Soll (2008) \\
\hline
\end{tabular}

